\title{
Long-Term Assessment of Right Ventricular Diastolic Filling in Patients with Pulmonic Valve Stenosis Successfully Treated in Childhood
}

\author{
Roger P. Vermilion, MD, A. Rebecca Snider, MD, A. Resai Bengur, MD, \\ and Jon N. Meliones, MD
}

Patients with severe pulmonic stenosis (PS) have right ventricular (RV) diastolic filling abnormalities detectable by tricuspid valve pulsed Doppler examination. To determine if these abnormalities persist long ferm after successful therapy of PS, 19 patients were examined $8 \pm 3$ years after PS therapy. At the time of follow-up Doppler examination, the PS gradient was $15 \pm 8 \mathrm{~mm} \mathrm{Hg}$. From the tricuspid valve inflow Doppler study, the following measurements were obtained at peak inspirationt peak velocities at rapid filling (peak E) and during atrial contraction (peak $A$ ), ratio of peak $E$ to peak $A$ velocities, $R V$ peak filling rate normalized for stroke volume, deceleration time, the fraction of filling in the first 0.33 of diastole as well as under the $E$ and $A$ waves, and the ratio of $E$ to $A$ area. Data from PS follow-up patients were compared with our previously reported data from 12 age-related control subjects and 14 untreated patients with PS. Patients with PS who were followed up had higher peak E velocity $(0.75 \pm 0.14$ vs $0.59 \pm 0.21$ $\mathrm{m} / \mathrm{s})$, lower peak $A$ velocity $(0.47 \pm 0.09$ vs 0.64 $\pm 0.28 \mathrm{~m} / \mathrm{s}$ ), higher $\mathrm{E} / \mathrm{A}$ velocity ratio (1.65 \pm 0.33 vs $1.11 \pm 0.52$ ), higher 0.33 area fraction $(0.52 \pm 0.08$ vs $0.34 \pm 0.14)$, lower $A$ area fraction $(0.29 \pm 0.06$ vs $0.45 \pm 0.21)$ and higher E/A area ratio $(2.48 \pm 0.82$ vs $1.73 \pm 1.05)$ than PS patients without treatment $(p<0.03)$. All Doppler indexes of the pationts with PS who were followed up were the same as those of the control subjects except for the peak $E$ velocity that was slightly higher $(0.75 \pm 0.14$ vs $0.63 \pm$ $0.11 \mathrm{~m} / \mathrm{s})$, the peak $A$ velocity that was slightly higher $(0.47 \pm 0.09$ vs $0.38 \pm 0.09 \mathrm{~m} / \mathrm{s})$ and the E/A area ratio that was slightly lower $(2.48 \pm$

From the Department of Pediatrics, C.S. Mott Children's Hospital, University of Michigan Medical Center, Ann Arbor, Michigan. Manuscript received March 4, 1991; revised manuscript received May 2, 1991.

Address for reprints: A. Rcbecca Snider, MD, F 1331, C.S. Mott Children's Hospital, University of Michigan Medical Center, Ann Arbor, Michigan 48109-0204.
0.82 vs $3.50 \pm 1.25)(p<0.03)$. Thus, at longterm follow-up, all RV diastolic filling indexes in successfully treated patients with PS improved compared with the untreated patients and approached values found in normal subjects. These data suggest that RV diastolic filling abnormalities in patients with PS are reversible over the long term and are therefore probably related to hypertrophy rather than fibrosis and scarring.

(Am J Cardiol 1991;68:648-652)

I n recent years, pulsed Doppler echocardiography has been used to assess right ventricular (RV) diastolic filling in a variety of diseases including valvular pulmonic stenosis (PS), pulmonary hypertension, constrictive pericarditis and cardiac tamponade. ${ }^{1-4}$ From the tricuspid valve Doppler recording, peak flow velocities, filling rates, and the proportion of filling in the various phases of diastole can be measured for the right ventricle. ${ }^{5}$ Normal values for the tricuspid valve Doppler indexes have been reported for the fetus, newborn infant and child. ${ }^{6-10}$ Recently, we reported the use of these Doppler indexes to detect abnormal patterns of RV diastolic filling in children with PS. ${ }^{4}$ Children with PS had a decreased percentage of the total Doppler area in the first third of diastole and an increased percentage of the total Doppler area under the A wave suggesting a relative shift of RV filling to late diastole. Furthermore, these diastolic filling abnormalities did not improve immediately after successful relief of the RV outflow obstruction, suggesting that afterload mismatch was not the direct cause of the observed diastolic filling abnormalities.

In this study, we hypothesized that RV hypertrophy is the cause of the impaired RV early diastolic relaxation found in children with valvular PS. Furthermore, if the RV diastolic filling abnormalities were caused by hypertrophy alone rather than fibrosis or scarring, then these abnormalities should return to normal as hypertrophy regresses over the long-term follow-up period after successful relief of PS. To test this hypothesis, we 
assessed RV diastolic filling using pulsed Doppler echocardiography in 19 patients who were examined $8 \pm 3$ years after successful relief of PS.

\section{METHODS}

Patients: The study included 19 patients who were examined $8 \pm 3$ years (mean \pm standard deviation) after successful relief of PS (Table I). These patients were randomly selected from all patients with PS undergoing routine follow-up evaluation in the outpatient clinic. Selection criteria included: (1) evidence by Doppler examination of successful relief of PS (peak gradient $<25 \mathrm{~mm} \mathrm{Hg}$ ), (2) absence of additional congenital defects such as tricuspid stenosis or left-to-right shunts that might alter the tricuspid valve Doppler recording, and (3) absence of significant tricuspid regurgitation that might mask RV diastolic filling abnormalities.

The PS follow-up group was 5 to 19 years old (mean 10.9) and weighed 18 to $83 \mathrm{~kg}$ (mean 45.2). Ten patients had previous pulmonary balloon valvuloplasty and 9 had surgical pulmonary valvotomy. Ten patients were treated before and 9 were treated after the age of 2 years. Data from PS patients at long-term follow-up were compared with our previously reported data from 12 age-related control subjects and 14 untreated patients with severe PS (Table I). ${ }^{4}$

Echocardiographic examinations: All study participants underwent a complete 2-dimensional and Doppler echocardiographic examination with the use of a 128-element phased-array ultrasound system and a variety of transducers appropriate for patient size. Tricuspid valve Doppler examinations were obtained from the parasternal short-axis or apical 4-chamber view. The sample volume was positioned so as to record the maximal velocities through the valve (usually near the tips of the leaflets). Based on prior studies with use of simultaneous thermister and tricuspid valve Doppler recordings, the velocities through the tricuspid valve vary significantly throughout the respiratory cycle with maximal velocities occurring at peak inspiration. ${ }^{8}$ Therefore, to obtain all Doppler measurements at a standard time in the respiratory cycle, only beats recorded at peak inspiration were used.

From the Doppler spectral recordings, the peak velocities during rapid ventricular filling (peak E) and during atrial contraction (peak $\mathrm{A}$ ) were measured, and thc ratio of peak $E$ to pcak $A$ velocities was calculated. To determine the Doppler pattern of RV filling, several areas under the Doppler tracing were measured using previously described methods: (1) the total area under the velocity envelope throughout diastole; (2) the area under the velocity curve for the first $33 \%$ of diastole (0.33 area); (3) the $\mathrm{E}$ area, or the triangular area

\begin{tabular}{|c|c|c|c|}
\hline & $\begin{array}{l}\text { Contirol } \\
\text { Subjects }\end{array}$ & PS F/U & PS Pre \\
\hline No. of patients & 12 & 19 & 14 \\
\hline Age (years) & $8.6(4.5-16)$ & $10.9(5-19)^{*}$ & $5.1(0.4-18) \dagger$ \\
\hline Weight (kg) & $32.7 \pm 15.4$ & $45.2 \pm 21.7^{*}$ & $21.6 \pm 20 \dagger$ \\
\hline Height (cril) & $133 \pm 20$ & $145 \pm 25^{*}$ & $103 \pm 32 \dagger$ \\
\hline
\end{tabular}

formed by extrapolating a straight line down from the peak E velocity to the baseline; and (4) the A area, or the triangular area formed in a similar manner under the peak A velocity. ${ }^{11}$ To determine the percentage of the total velocity envelope occupied by the individual areas, the area or filling fractions were calculated as the individual areas divided by the total area under the Doppler tracing. Also, the ratio of $\mathrm{E}$ and $\mathrm{A}$ areas was calculated. The peak filling rate normalized for stroke volume was calculated as the peak E velocity divided by the total velocity time integral, ${ }^{12}$ and the deceleration time was measured from the peak $E$ velocity to the time when the Doppler curve returned from the peak $E$ velocity to the baseline. ${ }^{13}$

Color, pulsed and continuous-wave Doppler examinations of the pulmonary valve were obtained from parasternal or subcostal views. With use of the view that provided the highest value for the peak velocity of the PS jet, the peak instantaneous pressure gradient across the pulmonary valve was calculated from the Bernoulli equation. ${ }^{6}$ Pulmonary insufficiency was diagnosed using color flow imaging techniques and was considered to be significant if the M-mode echocardiographic examination showed evidence of paradoxical septal motion or RV end-diastolic dimension $>95 \%$ for body surface area, or both. ${ }^{14}$

All Doppler examinations were recorded at a paper speed of $100 \mathrm{~mm} / \mathrm{s}$. The Doppler areas were traced from the paper recording using a digitizing tablet with a crosswire cursor, a personal computer and commercially available computer software. The Doppler velocities and areas were measured by tracing the outermost border of the spectral recordings.

Statistical analysis: Three cardiac cycles were measured and averaged to obtain each Doppler value. Statistical comparisons between the PS follow-up patients and the control subjects and between the untreated PS patients and the PS follow-up patients were obtained using unpaired $t$ tests and Bonferroni's correction for multiple comparisons. To determine if differences in RV diastolic filling patterns existed betwecn different patients in the PS follow-up group, the group was divided into several subgroups which were then compared using unpaired $t$ tests. Subgroup analyses included: (1) comparison of PS follow-up patients $>2$ years old at 


\begin{tabular}{|c|c|c|c|}
\hline Measurement & $\begin{array}{l}\text { Control } \\
\text { Subjects }\end{array}$ & PS F/N & PS Pre \\
\hline Peak E (m/s) & $0.63 \pm 0.11$ & $0.75 \perp 0.14^{*} \dagger$ & $0.59 \pm 0.21$ \\
\hline Peak $A(\mathrm{~m} / \mathrm{s})$ & $0.38 \pm 0.09$ & $0.47 \pm 0.09 * \dagger$ & $0.64 \pm 0.28^{*}$ \\
\hline E/A vel. & $1.74 \pm 0.51$ & $1.65 \pm 0.33 \dagger$ & $1.11 \pm 0.52^{\star}$ \\
\hline Total VTI (m) & $0.12 \pm 0.02$ & $0.13 \pm 0.03$ & $0.12 \pm 0.03$ \\
\hline 0.33 area $\mathrm{fx}$ & $0.51 \pm 0.12$ & $0.52 \pm 0.08 \dagger$ & $0.34 \pm 0.14^{*}$ \\
\hline Earea $f x$ & $0.71 \pm 0.08$ & $0.67 \pm 0.07$ & $0.57 \pm 0.19 *$ \\
\hline$A$ area $f x$ & $0.24 \pm 0.10$ & $0.29 \pm 0.06 \dagger$ & $0.45 \pm 0.21^{*}$ \\
\hline $\mathrm{E} / \mathrm{A}$ area & $3.50 \pm 1.25$ & $2.48 \pm 0.82^{*} \dagger$ & $1.73 \pm 1.05^{*}$ \\
\hline Decel. time (s) & $0.14 \pm 0.02$ & $0.12 \pm 0.02 \dagger$ & $0.09 \pm 0.04^{*}$ \\
\hline PFR/SV (SV/s) & $5.23 \pm 0.56$ & $5.79 \pm 1.08$ & $5.28 \pm 1.96$ \\
\hline Heart rate (beats $/ \mathrm{min}$ ) & $77 \pm 13$ & $75 \pm 13 \dagger$ & $99 \pm 27^{*}$ \\
\hline \multicolumn{4}{|c|}{ 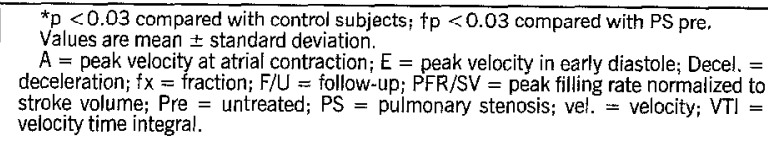 } \\
\hline
\end{tabular}

the time of therapy and those $<2$ years at the lime of therapy; (2) comparison of PS follow-up patients treated with surgery to those treated with balloon valvuloplasty; and (3) analysis of a subgroup of PS follow-up patients formed by exclusion of all patients with significant pulmonary insufficiency and RV diastolic dimension $>95 \%$ for body surface area. A two-tailed $p$ value $<0.03$ was used to indicate a significant intergroup difference. All values are mean \pm standard deviation.

\section{RESULTS}

Patients: The PS follow-up patients did not differ from the control subjects in age, height, weight or heart rate. Compared with untreated PS patients, the PS follow-up patients were older, had greater heights and weights, and had slower heart rates. Before treatment, the PS follow-up patients had the same pulmonary valve gradient as the untreated PS patients $(67 \pm 18$ vs $71 \pm 35 \mathrm{~mm} \mathrm{Hg}, \mathrm{p}=0.66$ ). After treatment, the PS follow-up patients had a significantly lower pulmonary valve gradient $(15 \pm 8 \mathrm{~mm} \mathrm{Hg})$.

Echocardiographic studies: COMPARISONS OF PULMONIC STENOSIS FOLLOW-UP PATIENTS WITH CONTROL SUBJECTS AND UNTREATED PULMONIC STENOSIS PATIENTS: Mean values for the Doppler measurements of the 3 patient groups are listed in Table II. The peak E velocity of the PS follow-up patients was significantly higher than that of the untreated PS patients and the control subjects. The peak A velocity of the PS follow-up patients was significantly lower than that of the untreated PS patients but still higher than that of control subjects. As a result, the E/A velocity ratio of PS follow-up patients was increased to a value not different from that found in normal subjects.

Compared with untreated PS patients, the 0.33 area fraction of the PS follow-up patients had increased significantly to a value not different from that found in control subjects. Likewise, the $\mathrm{E}$ area fraction of the PS follow-up patients was higher than that of the untreated PS patients $(p=0.05)$ and the same as that of the control subjects. The A area fraction of the PS followup patients had decreased significantly compared with that of untreated PS patients and was the same as that of normal subjects. As a result, the E/A area ratio of the PS follow-up group was significantly higher than that of untreated PS patients but did not quite reach the value found in normal subjects.

The deceleration time of the PS follow-up patients was longer than that found in the untreated PS patients but the same as that found in normal subjects. The normalized peak filling rates of the 3 patient groups were not significantly different.

SUBGROUP ANALYSIS: To determine the effect of age at the time of treatment on the observed Doppler findings, the PS follow-up group was divided into 2 subgroups: (1) patients $>2$ years old at the timle of therapy $(n=10)$, and (2) patients $<2$ years old at the time of therapy $(n=9)$. No differences were found in any diastolic filling indexes between the 2 subgroups.

To determine the effect of the type of therapy on the observed Doppler findings, the PS follow-up group was divided into 2 subgroups: (1) patients treated with surgery $(n=9)$, and (2) patients treated with balloon valvuloplasty $(n=10)$. No differences were found in any of the RV diastolic filling indexes between the 2 subgroups.

To determine if significant pulmonary insufficiency had an effect on the observed Doppler findings, a subgroup of PS follow-up patients was formed by excluding all patients $(n=4)$ with pulmonary insufficiency and RV diastolic dimension $>95 \%$ for body surface area. Elimination of these 4 patients did not change any of the statistical comparisons between the PS follow-up patients and the untreated PS and control groups.

\section{DISCUSSION}

In a previous study, we showed that children with severe PS have RV diastolic filling abnormalities detectable with Doppler echocardiography. ${ }^{4}$ In these children, the tricuspid Doppler examination showed a decreased percentage of the total Doppler area in the first third of diastole and an increased percentage of the total Doppler ared under the A wave, suggesting a relative shift of RV filling to late diastole. This abnormal tricuspid Doppler pattern resembles the mitral Doppler pattern I observed by Appleton et $\mathrm{al}^{13}$ in patients with impaired left ventricular early diastolic relaxation and normal left ventricular filling pressures. Immediately after balloon valvuloplasty and successful relief of the high afterload, RV diastolic filling abnormalities per- 
sisted, suggesting that afterload mismatch was not the cause of the filling abnormalities. In this long-term follow-up study, all RV diastolic filling indexes in successfully treated PS patients improved compared with untreated PS patients, and approached values found in normal subjects. These data suggest that RV diastolic filling abnormalities in PS patients are reversible and are, therefore, probably related to hypertrophy rather than fibrosis and scarring. RV mass was not assessed owing to the lack of an accurate means of measuring it noninvasively; however, all untreated PS patients had echocardiographic evidence of severe RV hypertrophy while the PS follow-up patients had little or no evidence of RV hypertrophy.

Possible mechanisms of diastolic filling abnormalities: Courtois et $\mathrm{a}^{15}$ recently showed that a pattern of diastolic apex to inflow pressure gradients cxists in the right ventricle during early and late diastole, similar to that reported in the left ventricle. ${ }^{16}$ In the right ventricle, however, the lowest early diastolic pressures are usually recorded in the outflow tract rather than in the apex. The form and timing of the regional ventricular pressure gradients found in their study suggest that mechanical suction of blood into the ventricular cavity is the primary mechanism of RV filling in early diastole. Mechanisms that probably contribute to mechanical suction include downward motion of the right ventricle during systole, active contraction of muscle fibers below equilibrium and resultant storage of elastic energy, and end-systolic deformation of the walls of the RV outflow tract. In the latter mechanism, blood continues to leave the ventricle after contraction has ended, thus causing the shape of the RV outflow tract to be distorted, elastic energy to be stored in the myocardium, and the walls of the outflow tract to recoil in early diastole. The importance of this mechanism is supported by the finding of the lowest early diastolic pressure in the RV outflow tract and the observation that significant narrowing of the outflow tract occurs at end-systole. ${ }^{15}$

In untreated PS patients, severe RV hypertrophy can lead to reduced end-systolic deformation of the RV outflow tract, less elastic recoil in early diastole, and a higher minimum RV pressure in early diastole. With a higher minimum RV diastolic pressure, the early diastolic pressure gradient and, thus, the peak $E$ velocity are decreased as was observed in our untreated PS patients. At long-term follow-up, the return of the peak $E$ velocity and the percent filling in early diastole toward normal values suggests that the end-systolic deformation of the outflow tract walls is restored as RV hypertrophy regresses.

In normal subjects, the tricuspid deceleration time is longer than the mitral deceleration time, suggesting that the thin-walled right ventricle is a less effective decelerator than the thicker-walled left ventricle. ${ }^{15}$ In untreated PS patients, we found a shortened tricuspid deceleration time compared with age-related normal subjects. It is likely that the thick-walled right ventricle of untreated PS patients quickly generates a reversed pressure gradient of sufficient magnitude to decelerate flow in early diastole. As hypertrophy regresses after successful relief of PS, the thin-walled right ventricle requires a longer period of time to generate a reverse pressure gradient, and thus the increase in deceleration time to normal values in our follow-up patients.

Factors affecting the tricuspid valve Doppler indexes: Diastolic indexes of RV relaxation can be influenced by several factors including age, heart rate, respiration and RV loading conditions. Throughout childhood, the tricuspid Doppler indexcs are independent of age beyond the neonatal period ${ }^{5-8}$ and, thus, it is unlikely that age contributed to the observed improvement in RV diastolic filling. In several recent studies, tricuspid Doppler indexes have been unrelated or only weakly related to heart rate. ${ }^{17,18}$ In this study, the improved $\mathrm{RV}$ filling cannot be explained on the basis of heart rate since the heart rates of the control and PS followup patients were not different. From expiration to inspiration in normal children, the tricuspid peak $E$ velocity increases by $26 \%$, the peak $\mathrm{A}$ velocity increases by $18 \%$, and the $\mathrm{E} / \mathrm{A}$ velocity ratio remains unchanged. ${ }^{8}$ In this study, the effects of respiration were eliminated by measuring only beats at maximal inspiration. The presence of tricuspid or pulmonary insufficiency may alter the early diastolic transvalvular pressure gradient and, thus, affect the tricuspid Doppler indexes. In this study, no patient had significant tricuspid insufficiency, and exclusion of 4 patients with pulmonary insufficiency did not alter the results.

Acknowledgment: We thank Kathlene Chmielewski, CMA, for editorial assistance, and Lyne Merida for technical assistance in the preparation of this manuscript.

\section{REFERENCES}

1. Appleton CP, Hatle LK, Popp RL. Demonstration of restrictive ventricular physiology by Doppler echocardiography. $J$ Am Coll Cardiol 1988;1 1:757-768. 2. Hatle LK, Appleton CP, Popp RL. Differentiation of constrictive pericarditis and restrictive cardiomyopathy by Doppler echocardiography. Circulation 1989 79:357-370.

3. Klein AL, Hatle LK, Burstow DJ, Taliercio CP, Seward JB, Kyle RA, Bailey KR, Gertz MA, Tajik AJ. Comprehensive Doppler assessment of right ventricular diastolic function in cardiac annyloidusis. J Am Coll Cardlol 1990;15:99-108. 4. Vermilion RP, Snider AR, Meliones JN, Peters J, Merida-Asmus L. Pulsed Doppler evaluation of right ventricular diastolic filling in children with pulmonary valve stenosis before and after balloon valvuloplasty. Am J Cardiol 1990 $66: 79-84$. 
5. Riggs TW, Rodriguez R, Snider AR, Batton D. Doppler echocardiographic evaluation of right and left ventricular diastolic function in normal neonates. $J \mathrm{Am}$ Coll Cardiol 1989:13:700-705.

6. Hatle L, Angelsen B. Doppler Ultrasound in Cardiology: Physical Principles and Clinical Applications. 2nd ed. Philadelphia: Lea \& Febiger, 1985.

7. Grenadier E, Lima CO, Allen HD, Sahn DJ, Vargas Barron J, Valdes-Cruz LM, Goldberg SJ. Normal intracardiac and great vessel Doppler flow velocities in infants and children. I Am Coll Cardiol 1984:4:343-350.

8. Riggs TW, Snider AR. Respiratory influence on right and left ventricular diastolic function in normal children. Am J Cardiol 1989;63:858-861.

9. Kenny JF, Plappert T, Doubilet P, Saltzman DH, Cartier M, Zollars L, Leatherman GF, St. John Suttun MG. Changes in intracardiac blood flow velocities and right and left ventricular stroke volumes with gestational age in the normal human fetus: a prospective Doppler echocardiographic study. Circulation 1986;74:1208-1216.

10. Huhta JC, Strasburger JF, Carpenter RJ, Reiter A, Abinader E. Pulsed Doppler fetal echocardiography. J Clin Ultrasound 1985;13:247-254.

11. Snider AR, Gidding SS, Rocchini AP, Rosenthal A, Dick M II, Crowley DC Peters J. Doppler evaluation of left ventricular diastolic filling in children with systemic hypertension. Am J Cardiol 1985;56:921-926.

12. Bowman LK, Forrester AL, Jaffe CC, Mattera J, Wackers FJT, Zaret BL.
Peak filling normalized to mitral stroke volume: a new Doppler echocardiographic filling index validated by radionuclide angiographic techniques. $J$ Am Coll Cardiol 1988:12:937-943.

13. Appleton CP, Hatle LK, Popp RL. Relation of transmitral flow velocity patterns to left ventricular diastolic function: new insights from a combined hemodynamic and Doppler echocardiographic study. I Am Coll Cardiol 1988; 12:426-440.

14. Roge CLL, Silverman NH, Hart PA, Ray RM. Cardiac structure growth pattern determined by echocardiography. Circulation 1978;57:285-290.

15. Courtois M, Barzilai B, Gutierrez F, Ludbrook PA. Characterization of regional diastolic pressure gradients in the right ventricle. Circulation 1990; 82:1413-1423.

16. Courtois M, Kovacs SJ Jr, Ludbrook PA. The trans-mitral pressure-flow velocity relationship: The importance of regional pressure gradients in the left ventricle. Circulation 1988;78:661-671.

17. Berman GO, Reichek N, Brownson D, Douglas PS. Effects of sample volume location, imaging view, heart rate and age on tricuspid velocimetry in normal subjects. Am J Cardiol 1990;65:1026-1030.

18. Zoghbi WA, Habib GB, Quinones MA. Doppler assessment of right ventricular filling in a normal population. Comparison with left ventricular filling dynamics. Circulation 1990;82:1316-1324. 